\title{
ACE2 as Drug Target of COVID-19 Virus Treatment, Simplified Updated Review
}

\author{
Gomaa Mostafa-Hedeab*1,2
}

\begin{abstract}
Background: Since its first appearance in December of 2019, regular updates around the world demonstrates that the number of new Corona Virus 2019 (COVID-19) cases are increasing rapidly, indicating that not only does COVID-19 exhibit a rapid spread pattern, but human intervention is necessary for its resolution. Up until today (27-5-2020) and according to the World Health Organization (WHO), the number of confirmed COVID-19 cases has surpassed 4.5 million with more than 307, 500 deaths. Almost all countries have been affected by COVID-19, and resultingly, various drug trials have been conducted, however, a targeted treatment remains to be made accessible to the public. Recently, Angiotensin-Converting Enzyme-2 (ACE2) has gained some attention for its discovery as a potential attachment target of COVID-19.

Methods: We reviewed the most recent evidence regarding ACE2 distribution and action, the binding mechanism of COVID-19 and its correlation to cellular injury, ACE2 polymorphisms and its association to fatal COVID-19 and susceptibility and, finally, current ACE2-based pharmacotherapies against COVID-19.

Results: Blocking the ACE2 receptor-binding domain (RBD) using a specific ligand can prevent COVID-19 from binding, and consequently cellular entry and injury. Comparatively, soluble ACE2, which has a higher affinity to COVID-19, can neutralize COVID-19 without affecting the homeostatic function of naturally occurring ACE2. Lastly, ACE2 mutations and their possible effect on the binding activity of COVID-19 may enable researchers to identify highrisk groups before they become exposed to COVID-19.

Conclusions: ACE2 represents a promising target to attenuate or prevent COVID-19 associated cellular injury.
\end{abstract}

Keywords: ACE, ACE2, COVID-19.

\section{$\mathrm{ACE}$ and $\mathrm{ACE} 2$}

Since the end of 2019, the rapid spread of the novel Severe acute respiratory syndrome coronavirus 2 (SARS-CoV-2), which first appeared in Wuhan, China, led to widespread severe respiratory infection and pneumonia, and a mortality rate of $1 \%-2.5 \%$ (1). ACE2 belongs to the ACE family, and ACE proteins, in particular, are zinc metallopeptidases. Moreover, the ACE2 gene is located on position $\mathrm{Xp} 22$ on chromosome $\mathrm{X}$ and contains 18 exons (2).

ACE2 is primarily expressed in arterial and venous endothelial cells, arterial smooth muscle (3), and oral mucosa (4). Jackman et al. (5) showed that in human pulmonary endothelial cells, angiotensin (Ang) (1-9) was significantly more active than Ang- (1-7), which enhanced the effect of ACE-resistant bradykinin analog on the beta receptor type-2 (B2) adrenergic receptor. In addition, Ang-(1-9) was found to augment arachidonic acid and nitric oxide (NO) release by kinin (5).

Though ACE2 is approximately $40 \%$ similar to the somatic form of ACE (2), they differ in biological function and substrate specificity (6).

ACE is located on chromosome 17 (7) and mediates the conversion from Ang I (inactive decapeptide) to Ang II (octapeptide active form) (8). Here is a list of the following actions that may occur as a consequence of this conversion:

- Ang II is potent vasoconstrictor (8) 


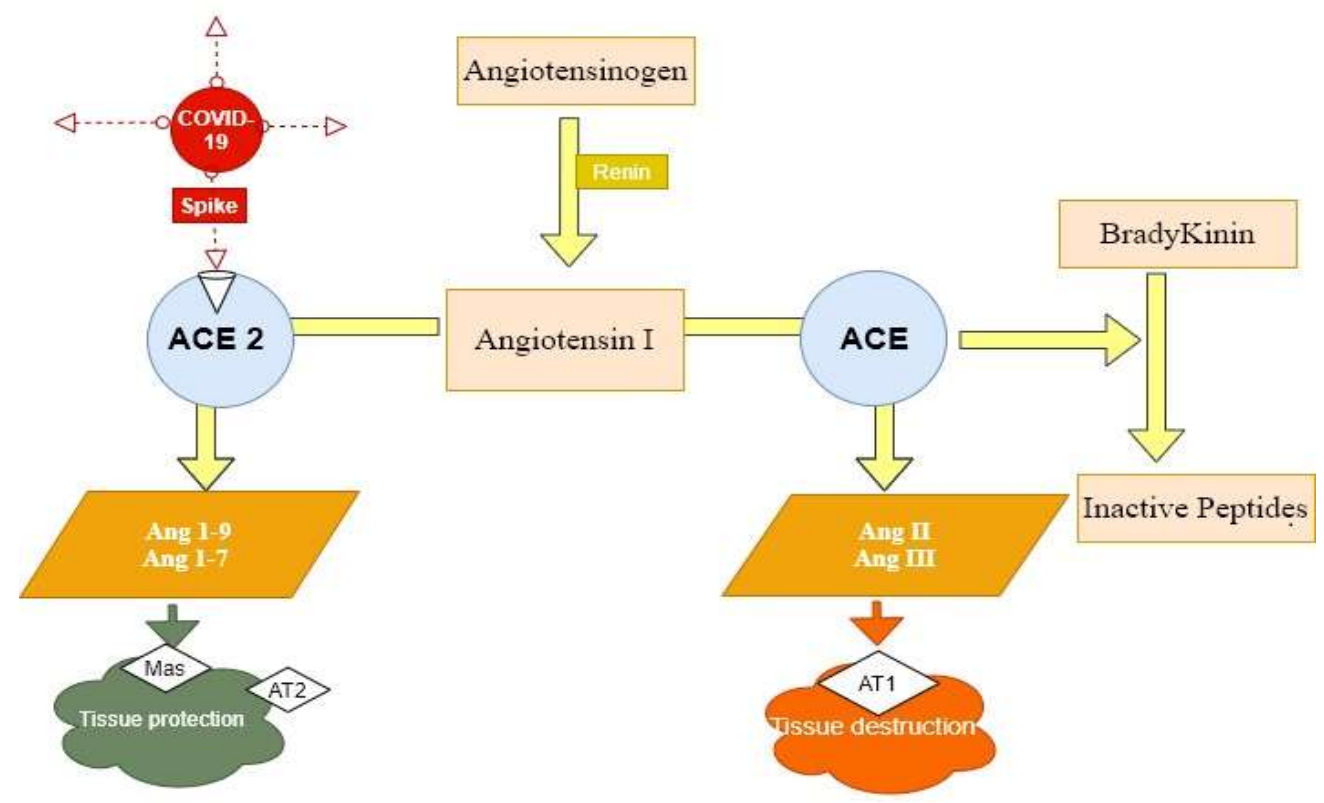

Fig. 1. Diagrammatic demonstration showed the main differences between ACE and ACE2 and its effect on COVID-19. COVID-19 bind specifically to ACE2 on cell membrane od different tissues, followed by ACE2 downregulation and COVID-19 cellular entry and consequent cytokine storm and lung tissue injury. ACE2 downregulation results in decrease Ang 1-9 and Ang 1-7 decreasing their tissue protection and leaving ACE destructive power unopposed that result in increasing the rate and extend of lung tissue injury.

- Preserves and prevents the degradation of bradykinin, a vasodilator peptide (9).

- Triggers the release of aldosterone which enhances sodium and water reabsorption by the kidneys (10).

- Enhances the action of anti-diabetic drugs such as dipeptidyl peptidase-4 (DPP4) (11). ACE2 does not degrade in the presence of bradykinin and it is not inhibited by classic ACE inhibitors (ACEIs) (12).

- Stimulates cell proliferation through the activation of various cytokines (13).

Bradykinin, a vasodilator that acts through the B2 receptor, is produced from its precursor kininogen by kallikrein, and subsequently degraded by ACE (14).

ACE2 is expressed in the membrane of tissues such as the heart, kidneys, lungs, intestine, and testis (15). ACE2 is also shown to be downregulated in the context of cyclic vomiting syndrome (CVS) related diseases (16).

ACE produces Ang-(1-7) via Ang II hydrolysis and Ang-(1-9) via Ang I hydrolysis. Ang-(1-7) is a vasodepressor peptide that antagonizes the vasopressor action of Ang II (17). Furthermore, Ang-(1-7) is converted into inactive Ang-(1-5) by ACE (6) or by neutral endopeptidases (12).

ACE2 activity may, therefore, counterbalance the effects of ACE by preventing the accumulation of Ang II in tissues where both ACE2 and ACE are expressed (18).
Moreover, Ang-(1-7) binds to the mitochondrial assembly (Mas) receptor, a G-protein-coupled receptor (GPCR), resulting in prostaglandin vasodilation and antiproliferative actions (19). The Mas receptor can hetero-oligomerize with the angiotensin II receptor type 1 (AT1) and act as a physiological antagonist of Ang II (20). Ang-(1-7) induces endothelial NO production via protein kinase $\mathrm{B}$ (Akt)-dependent pathways (21). Ang-(1-9) may be converted to Ang(1-7) by ACE (12) (Fig. 1).

Interestingly, pancreatic ACE2 plays a crucial role in glycaemic control (22). Downregulation of renal ACE2 was shown to be linked to the decline in renal disease and diabetic nephropathy (23). ACE2 transcription is controlled by various DNA binding proteins including Sirtuin 1 (SIRT1) (24).

The human ACE2 was discovered during human heart failure and in lymphoma complementary deoxyribonucleic acid (cDNA) libraries (12). Previously, ACE2 was considered to have no role in immune cell function, however, Zhao et al. recently discovered ACE2 micro ribonucleic acid (mRNA) in CD 14+ and CD16+- human monocytes (25).

In a bleomycin-induced pulmonary fibrosis animal model, the intraperitoneal injection of recombinant human ACE2 treatment decreased lung inflammation and fibrosis and had improved lung function (26). In a 
rat model for ischemic heart disease, the subcutaneous infusion of diminazene aceturate (DIZE) significantly increased cardiac ACE2 mRNA expression and ACE2 protein catalytic activity, reduced ACE mRNA expression, and improved cardiac remodeling (27).

Further, the rate of ACE2 expression increased in diabetic and hypertensive patients receiving ACEI or angiotensin II type-I receptor blockers (ARBs) (28) (29).

\section{Link between ACE2 Receptors and COVID-19}

COVID-19 is a positive single-stranded RNA virus (+ssRNA) that causes severe respiratory syndrome in humans (30). COVID-19 binds to their cellular target via ACE2 (28), and its receptor recognition and fusion of cellular membrane are being mediated by SARSCoV spike glycoprotein (SP) (31). SARS-CoV-2 SP binds to the RBD of ACE2 (32).

The similarity between SARS-CoV2 and SARSCOV1 (33), and the similarity between SARS-CoV2 SP and the RBD of ACE2, indicates a strong binding affinity to human ACE2 in both cases (34).

Furthermore, SARS-CoV2 has a stronger affinity to ACE2 compared to SARS-CoV, a factor that likely caused increased human to human transmission of SARS-CoV2 (28).

The binding of the +ssRNA virus to the RBD of ACE2 determines viral entry into the cell and the rate of cell injury (35), which is directly proportional to ACE2 expression (36).

\section{COVID-19 binding to ACE2 and Tissue injury}

ACE2 receptors are found in various extrapulmonary tissues including the heart, kidneys, endothelium, and intestine (15) (37). When COVID-19 binds to the ACE2 receptor, a cytokine storm and the inflammatory process is initiated, and the lung was found to be the most affected site. This begs the question, why?

The outcome of the lung was explained by Zhao et al. who demonstrated that alveolar epithelial type II cells (AECII) may express $83 \%$ of ACE2 in nomal lung tissue donors (38). Moreover, using gene ontology analysis, they found that AEC2 expressing cells carried several viral process-related genes including viral replication and assembly (38), which could explain the presence of viral replication in the lung tissue and initiation of lung injury.

In addition, also ACE2 is expressed in the gastrointestinal tract (GIT), specifically the luminal surface of epithelial tissue, and acts as co-receptor for amino acid and nutrient uptake (39). This finding suggests that we should consider the feco-oral transmission route and COVID-19 related-GIT symptoms. Indeed, the widespread distribution of ACE2 across more than one organ may explain the observed multiorgan dysfunction in COVID-19 patients (40) (41).

\section{ACE2 gene polymorphisms}

ACE2 gene polymorphisms are linked to several diseases, particularly Asian populations, which may play a role in ACE2 expression and increased risk of COVID-19 infection (42). The variability in ACE2 mRNA expression compared to race is not well understood, and there seems to be conflicting evidence in the literature. Firstly, Zhao et al. showed that the lungs of Asian males expressed higherACE2 mRNA compared to their female counterparts. Zhao et al. also found that Asian populations expressed higher ACE2 mRNA compared to Caucasian or African-American populations (38), whereas, Gai et al. showed that there was no significant difference in ACE2 mRNA expression between Asian and Caucasian populations (43). To clarify these conflicting results, the exact genetic basis of ACE2 expression in different populations warrants future investigation (44).

\subsection{ACE2 Gene polymorphisms and diseases}

As previously mentioned, ACE2 is a vasodilator agent that opposes the action of Ang II. The disruption of ACE2 results in a relative increase in Ang II levels and a decrease in cardiac performance (45).

Previous studies correlate the association of diminished cardiac ACE2 with diabetic heart disease, hypertension (HT) (46) (47) and dyslipidemia (48).

The association between ACE2 gene polymorphisms among different species and certain diseases are summarized in Table 1. Most polymorphisms are associated with a specific type of HT. 
Table 1. Association between different ACE2 SNPs and diseases in different populations.

\begin{tabular}{lll}
\hline Population & Association & Reference \\
\hline Chinese population & $\begin{array}{l}\text { rs2074192 was associated with Essential Hypertension (EH) } \\
\text { rs4240157, rs4646155, and rs4830542 were associated with EH-and } \\
\text { hypertension-related AF and left atrial }\end{array}$ & $(49)$ \\
\hline Chinese population & rs2106809 determine the efficacy of ACEI in hypertensive patients & $(50)$ \\
\hline Chinese population & No association with either hypertension or orthostatic hypertension & $(51)$ \\
\hline Chinese population & A1075G associated with hypertension & $(52)$ \\
\hline Canadian Nicotine Dependence in & $\begin{array}{l}\text { rs2074192, rs233575, and rs2158083 variants associated with pathological } \\
\text { Teens Canadian }\end{array}$ & $(53)$ \\
\hline $\begin{array}{l}\text { Nicotine Dependence Canadian of } \\
\text { European descent }\end{array}$ & $\begin{array}{l}\text { rs2074192 and rs233575 associated with both Systolic Blood Pressure } \\
\text { (SBP) and diastolic Blood Pressure(DBP) and rs2158083 was associated }\end{array}$ & $(53)$ \\
\hline French Canadian Males Nicotine & with SBP only \\
Dependence & rs233575 and rs2158083 were associated with DBP & $(53)$ \\
\hline Canadian females of European & rs2074192, rs233575, and rs2158083 associated with a change in SBP & $(53)$ \\
\hline Descent Nicotine Dependence & rs2106809 affect benazepril efficacy. & $(54)$ \\
\hline Chinese & rs21068809 association HT & $(55)$ \\
\hline Indian & ACE2 G8790A polymorphisms reveal susceptibility to HT & $(56)$ \\
\hline Brazilian patients & $\begin{array}{l}\text { rs2048683 is associated with cardiovascular riskin Uygurs with type2 } \\
\text { diabetes mellitus. }\end{array}$ & $\begin{array}{l}\text { (57) } \\
\text { Chinese individuals }\end{array}$ \\
\hline Uygurs & $\begin{array}{l}\text { Hs2074192 and rs2106809 are associated with Left Ventricular } \\
\text { Hypertrophy in hypertensive patients. }\end{array}$ \\
\hline Chinese & (58) & $(59)$ \\
\hline
\end{tabular}

\subsection{ACE2 receptor polymorphism and coronaviruses infection}

In a murine model, Wysocki et al. found that the expression level of ACE2 may be affected by ACE2 mutations (60). In a separate study, increased cardiovascular tissue damage in mice with a deleted ACE2 gene was found to be

concomitant to increased Ang II levels (61). In Iran, the presence of SARS-CoV-2-induced inflammation was explained by the attenuation of Ang II conversion to Ang (1-7) via ACE2 (62).

Cell type II transmembrane protein dipeptidyl peptidase 4 (DPP4/CD26) is required for COVID-19 to bind to the host cell through the SP (63). Within endosomes, the SP activates cellular transmembrane serine protease 2 (TMPRSS2) and cysteine protease cathepsin L. Then, the kallikrein-related peptidase 5
(KLK5) cleaves dipeptidyl-peptidase-4 (DPP4) and releases it into circulation in its soluble form (64).

Among the 14 mutations reported within the DPP4 gene, four polymorphisms (K267E, K267N, A291P, and D346-348) were reported to decrease the binding and penetration power of the Middle East respiratory syndrome (MERS-CoV) into target cells, leading to decreased viral replication (65).

Among the 32 identified variants of ACE2 by Cao and colleagues, seven mutant points were considered to affect SARS-CoV-2 infections. Thus, some individuals may be more resistant to SARS-CoV-2 infections than others (44), however, these findings require further confirmation.

A recent publication by Asselta et al. stated that 
TMPRSS2 variants, but not ACE2 gene polymorphisms, determines the severity and progression of COVID-19 (66).

Calcagnile et al. studied the potential interaction between ACE2 single nucleotide polymorphisms and COVID-19 S-glycoproteins. They found that the S19P (rs73635825) mutation, which is more common in African populations, may genetically protect against COVID-19. In addition, they found that K26R SNPs (rs75548401), which is more prevalent in individuals with a European background, may be predisposed to severe SARS-CoV-2 infection (67), however, a clinical association may be required to prove this conclusion.

\section{Recombinant ACE2}

The binding of COVID-19 to the ACE2 receptor binding site which is located on the cell membrane is followed by the downregulation of ACE2 and COVID-19 entry, and, therefore, the initiation and exacerbation of lung injury [10].

This raises the question of whether it is possible to neutralize COVID-19 to prevent cell entry by administrating soluble ACE2.

Yu et al. state that soluble ACE2 could theoretically result in COVID-19 neutralization and decrease the renin-angiotensin system (RAS)-induced lung injury during the acidic phase or ventilation (68).

Moreover, one clinical trial showed that recombinant human ACE2 (rhACE2; APN01, GSK2586881) is safe and reduced ang II proteolytic target peptide and interleukin-6 (IL-6) substantially when given to healthy volunteers suffering from acute respiratory distress syndrome (ARDs) (69) (70). Based on these conclusions, soluble ACE2 could be a possible therapeutic target in COVID-19 patients.

\section{COVID-19 interfaces with ACE2}

The COVID-19 RBD is similar to SARS-CoV-RBD (34), however, several sequence variations and conformational deviations can be found in their respective interfaces with ACE2.

When Yan et al. compared the interaction interface of SARS-CoV-2-RBD and SARS-CoV-RBD with ACE2, it was suggested that some variations strengthened the interaction between SARS-CoV-2RBD and ACE2, while others likely weakened the interaction (71). He demonstrated that a change in amino acids, such as Valine 404 (Val404) to Lysine
317 (Lys317) resulted in a tighter association due to the formation of a salt bridge in ACE2 between Lys317 and Aspartic acid 30 (Asp30). Furthermore, the change from Leucine 472 (Leu472) to Phenylalanine 486 (Phe486) strengthened the van der Waals forces with Methionine (Met82) (71).

Comparatively, the replacement of Arginine 426 (Arg426) with Asparagine 439 (Asn439) in ACE2 appeared to weaken the interaction due to the loss of an important salt bridge with Asp32 (71).

He concluded that the development of a ligand or antibody could be carried out based on protein structure. Taken together, synthesizing an agent with an enhanced affinity to either ACE2 or COVID19 could attenuate virulence and infection (71).

\section{ACE2-based pharmacotherapy for COVID-19}

COVID-19 could be attacked or at least partially attenuated by one of the following strategies:

- Blocking the COVID-19 ACE2 receptor binding site either by specific ligand or antibody.

- The soluble form of ACE2 will neutralize COVID19 by binding to its surface, and, thus, attenuate its binding to ACE2 on the cell surface and decreasing collateral tissue damage, specifically in the lungs.

- Using a structural based design strategy that considers the interface between SARS-CoV-2 and SARS-CoV with ACE2 (71) will allow us to synthesize a novel neutralizing agent (soluble ACE2) that strongly adheres to COVID-19 compared to human ACE2

- Developing a COVID-19 spike vaccine that is based on its protein structure will prevent it from binding to the ACE2 receptor binding site.

\section{Conclusion}

A suitable target that can help attenuate or prevent cellular injury associated with COVID-19 infection is ACE2 since it is the known binding site for COVID19. By blocking the RBD of ACE2 with a specific ligand, we can prevent COVID-19 binding and, consequently, cellular entry and injury. Overcoming possible constraints, and achieving a soluble ACE2 molecule with a higher affinity to COVID-19 could neutralize COVID-19 without affecting the beneficial effects of naturally occurring ACE2. Lastly, ACE2 mutations and their associated effect on the binding activity of COVID-19 could enable us to identify groups at higher risk of developing COVID-19. 


\section{References}

1. Huang C, Wang Y, Li X, Ren L, Zhao J, Hu Y, et al. Clinical features of patients infected with 2019 novel coronavinus in Wuhan, China. The lancet. 2020;395(10223):497-506.

2. Tipnis SR, Hooper NM, Hyde R, Karran E, Christie G, Turner AJ. A human homolog of angiotensin-converting enzyme. cloning and functional expression as a captopril-insensitive carboxypeptidase. J Biol Chem. 2000;275(43):33238-43.

3. Hamming I, Timens W, Bulthuis M, Lely A, Navis $\mathrm{G}$, van Goor H. Tissue distribution of ACE2 protein, the functional receptor for SARS coronavirus. A first step in understanding SARS pathogenesis. J Pathol. 2004;203(2):631-637.

4. Xu H, Zhong L, Deng J, Peng J, Dan H, Zeng X, et al. High expression of ACE2 receptor of 2019-nCoV on the epithelial cells of oral mucosa. International Joumal of Oral Science. 2020;12(1):1-5.

5. Jackman HL, Massad MG, Sekosan M, Tan F, Brovkovych V, Marcic BM, et al. Angiotensin 1-9 and 1-7 release in human heart: role of cathepsin A. Hypertension. 2002;39(5):976-81.

6. Vickers C, Hales P, Kaushik V, Dick L, Gavin $\mathrm{J}$, Tang $\mathrm{J}$, et al. Hydrolysis of biological peptides by human angiotensin-converting enzyme-related carboxypeptidase. J Biol Chem. 2002;277(17):14838-43.

7. Sayed-Tabatabaei F, Oostra B, Isaacs A, Van Duijn C, Witteman J. ACE polymorphisms. Circ Res. 2006;98(9):1123-33.

8. Turner A. Exploring the structure and function of zinc metallopeptidases: old enzymes and new discoveries. Biochem Soc Trans. 2003;31(Pt 3):723-7.

9. Jaspard E, Wei L, Alhenc-Gelas F. Differences in the properties and enzymatic specificities of the two active sites of angiotensin I-converting enzyme (kininase II). Studies with bradykinin and other natural peptides. J Biol Chem. 1993;268(13):9496-503.

10. Brewster UC, Perazella MA. The reninangiotensin-aldosterone system and the kidney: effects on kidney disease. The American joumal of medicine. 2004;116(4):263-272.

11. Aroor A, Zuberek M, Duta C, Meuth A, Sowers JR, Whaley-Connell A, et al. Angiotensin II stimulation of DPP4 activity regulates megalin in the proximal tubules. Int J Mol Sci. 2016;17(5):780.

12. Donoghue M, Hsieh F, Baronas E, Godbout K, Gosselin M, Stagliano N, et al. A novel angiotensin- converting enzyme-related carboxypeptidase (ACE2) converts angiotensin I to angiotensin 1-9. Circ Res. 2000;87(5):e1-9.

13. Carluccio M, Soccio M, De Caterina R. Aspects of gene polymorphisms in cardiovascular disease: the renin-angiotensin system. Eur $\mathbf{J}$ Clin Invest. 2001;31(6):476-88.

14. Turner AJ, Tipnis SR, Guy JL, Rice GI, Hooper NM. ACEH/ACE2 is a novel mammalian metallocarboxypeptidase and a homologue of angiotensin-converting enzyme insensitive to ACE inhibitors. Canadian joumal of physiology and pharmacology. 2002;80(4):346-53.

15. Gu J, Gong E, Zhang B, Zheng J, Gao Z, Zhong $Y$, et al. Multiple organ infection and the pathogenesis of SARS. J Exp Med. 2005;202(3):415-424.

16. Raizada MK, Ferreira AJ. ACE2: a new target for cardiovascular disease therapeutics. J Cardiovasc Pharmacol. 2007;50(2):112-9.

17. Rice GI, Thomas DA, Grant PJ, Turner AJ, Hooper NM. Evaluation of angiotensin-converting enzyme (ACE), its homologue ACE2 and neprilysin in angiotensin peptide metabolism. Biochem $\mathrm{J}$. 2004;383(Pt 1):45-51.

18. Riviere G, Michaud A, Breton C, VanCamp G, Laborie $\mathrm{C}$, Enache $\mathrm{M}$, et al. Angiotensin-converting enzyme 2 (ACE2) and ACE activities display tissuespecific sensitivity to undernutrition-programmed hypertension in the adult rat. Hypertension. 2005;46(5):1169-74.

19. Santos RA, e Silva ACS, Maric C, Silva DM, Machado RP, de Buhr I, et al. Angiotensin-(1-7) is an endogenous ligand for the $\mathrm{G}$ protein-coupled receptor Mas. Proceedings of the National Academy of Sciences. 2003;100(14):8258-63.

20. Kostenis E, Milligan G, Christopoulos A, SanchezFerrer CF, Heringer-Walther S, Sexton PM, et al. Gprotein-coupled receptor Mas is a physiological antagonist of the angiotensin II type 1 receptor. Circulation. 2005;111(14):1806-13.

21. Sampaio WO, Souza dos Santos RA, FariaSilva R, da Mata Machado LT, Schiffrin EL, Touyz RM. Angiotensin-(1-7) through receptor Mas mediates endothelial nitric oxide synthase activation via Akt-dependent pathways. Hypertension. 2007;49(1):185-92.

22. Pedersen KB, Chhabra KH, Nguyen VK, Xia H, Lazartigues E. The transcription factor HNFlalpha 
induces expression of angiotensin-converting enzyme 2(ACE2) in pancreatic islets from evolutionarily conserved promoter motifs. Biochim Biophys Acta. 2013;1829(11):1225-35.

23. Reich HN, Oudit GY, Penninger JM, Scholey JW, Herzenberg AM. Decreased glomerular and tubular expression of ACE2 in patients with type 2 diabetes and kidney disease. Kidney Int. 2008;74(12):1610-6.

24. Patel VB, Zhong J-C, Grant MB, Oudit GY. Role of the ACE2/angiotensin 1-7 axis of the reninangiotensin system in heart failure. Circ Res. 2016;118(8):1313-1326.

25. Rutkowska-Zapała M, Suski M, Szatanek R, Lenart M, Węglarczyk K, Olszanecki R, et al. Human monocyte subsets exhibit divergent angiotensin I-converting activity. Clinical \& Experimental Immunology. 2015;181(1):126-32.

26. Rey-Parra G, Vadivel A, Coltan L, Hall A, Eaton $\mathrm{F}$, Schuster M, et al. Angiotensin converting enzyme 2 abrogates bleomycin-induced lung injury. J Mol Med (Berl). 2012;90(6):637-47.

27. Qi Y, Zhang J, Cole-Jeffrey CT, Shenoy V, Espejo A, Hanna M, et al. Diminazene aceturate enhances angiotensin-converting enzyme 2 activity and attenuates ischemia-induced cardiac pathophysiology. Hypertension. 2013;62(4):746-52.

28. Wan Y, Shang J, Graham R, Baric RS, Li F. Receptor Recognition by the Novel Coronavirus from Wuhan: an Analysis Based on Decade-Long Structural Studies of SARS Coronavirus. J virol. 2020;94(7):e00127-20.

29. Li XC, Zhang J, Zhuo JL. The vasoprotective axes of the renin-angiotensin system: Physiological relevance and therapeutic implications in cardiovascular, hypertensive and kidney diseases. Pharmacol Res. 2017;125(Pt A):21-38.

30. Zhu N, Zhang D, Wang W, Li X, Yang B,

Song J, et al. A novel coronavirus from patients with pneumonia in China, 2019. N Engl J Med. 2020;382(8):727-733.

31. Simmons G, Zmora P, Gierer S, Heurich A, Pohlmann S. Proteolytic activation of the SARScoronavirus spike protein: cutting enzymes at the cutting edge of antiviral research. Antiviral Res. 2013;100(3):605-14.

32. Wrapp D, Wang N, Corbett KS, Goldsmith JA, Hsieh C-L, Abiona O, et al. Cryo-EM structure of the 2019-nCoV spike in the prefusion conformation. Science. 2020;367(6483):1260-1263.
33. Xu X, Chen P, Wang J, Feng J, Zhou H, Li X, et al. Evolution of the novel coronavirus from the ongoing Wuhan outbreak and modeling of its spike protein for risk of human transmission. Sci China Life Sci. 2020;63(3):457-460.

34. Li F, Li W, Farzan M, Harrison SC. Structure of SARS coronavirus spike receptor-binding domain complexed with receptor. Science. 2005;309(5742):1864-8.

35. Yang X-h, Deng W, Tong Z, Liu Y-x, Zhang L-f, $\mathrm{Zhu} \mathrm{H}$, et al. Mice transgenic for human angiotensinconverting enzyme 2 provide a model for SARS coronavirus infection. Comp Med. 2007;57(5):450-9.

36. Liu CX, Hu Q, Wang Y, Zhang W, Ma ZY, Feng $\mathrm{JB}$, et al. Angiotensin-Converting Enzyme (ACE) 2 Overexpression Ameliorates Glomerular Injury in a Rat Model of Diabetic Nephropathy: A Comparison with ACE Inhibition. Mol Med. 2011;17(1-2):59-69.

37. Ding Y, He L, Zhang Q, Huang Z, Che X, Hou J, et al. Organ distribution of severe acute respiratory syndrome (SARS) associated coronavirus (SARS-CoV) in SARS patients: implications for pathogenesis and virus transmission pathways. J Pathol. 2004;203(2):622-630.

38. Zhao Y, Zhao Z, Wang Y, Zhou Y, Ma Y, Zuo W. Single-cell RNA expression profiling of ACE2, the putative receptor of Wuhan 2019-nCov. BioRxiv. 2020.

39. Hashimoto T, Perlot T, Rehman A, Trichereau J, Ishiguro $\mathrm{H}$, Paolino $\mathrm{M}$, et al. ACE2 links amino acid malnutrition to microbial ecology and intestinal inflammation. Nature. 2012;487(7408):477-81.

40. Wang D, Hu B, Hu C, Zhu F, Liu X, Zhang J, et al. Clinical Characteristics of 138 Hospitalized Patients With 2019 Novel Coronavirus-Infected Pneumonia in Wuhan, China. Jama. 2020;323(11):1061-1069.

41. Corman VM, Landt O, Kaiser M, Molenkamp R, Meijer A, Chu DK, et al. Detection of 2019 novel coronavirus (2019-nCoV) by real-time RT-PCR. Euro Surveill. 2020;25(3):2000045.

42. Fang L, Karakiulakis G, Roth M. Are patients with hypertension and diabetes mellitus at increased risk for COVID-19 infection?. Lancet Respir Med. 2020;8(4):e21.

43. Cai G. Bulk and single-cell transcriptomics identify tobacco-use disparity in lung gene expression of ACE2, the receptor of 2019-nCov. MedRxiv. 2020.

44. Cao Y, Li L, Feng Z, Wan S, Huang P, Sun X, et al. Comparative genetic analysis of the novel 
coronavirus (2019-nCoV/SARS-CoV-2) receptor ACE2 in different populations. Cell Discov. 2020;6:11.

45. Crackower MA, Sarao R, Oudit GY, Yagil C, Kozieradzki I, Scanga SE, et al. Angiotensinconverting enzyme 2 is an essential regulator of heart function. Nature. 2002;417(6891):822-8.

46. Diez-Freire C, Vazquez J, Correa de Adjounian $\mathrm{MaF}$, Ferrari MF, Yuan L, Silver X, et al. ACE2 gene transfer attenuates hypertension-linked pathophysiological changes in the SHR. Physiol Genomics. 2006;27(1):12-9.

47. Tikellis C, Pickering R, Tsorotes D, Du X-J, Kiriazis H, Nguyen-Huu T-P, et al. Interaction of diabetes and ACE2 in the pathogenesis of cardiovascular disease in experimental diabetes. Clin Sci (Lond). 2012;123(8):519-29.

48. Velkoska E, Patel SK, Burrell LM. Angiotensin converting enzyme 2 and diminazene: role in cardiovascular and blood pressure regulation. Curr Opin Nephrol Hypertens. 2016;25(5):384-95.

49. Luo Y, Liu C, Guan T, Li Y, Lai Y, Li F, et al. Association of ACE2 genetic polymorphisms with hypertension-related target organ damages in south Xinjiang. Hypertens Res. 2019;42(5):681-689.

50. Chen Y, Liu D, Zhang P, Zhong J, Zhang C, Wu $\mathrm{S}$, et al. Impact of ACE2 gene polymorphism on antihypertensive efficacy of ACE inhibitors. J Hum Hypertens. 2016;30(12):766-771.

51. Fan Xh, Wang Yb, Wang H, Sun K, Zhang W-1, Song $\mathrm{Xd}$, et al. Polymorphisms of angiotensinconverting enzyme (ACE) and ACE2 are not associated with orthostatic blood pressure dysregulation in hypertensive patients. Acta Pharmacol Sin. 2009;30(9):1237-44.

52. Niu W, Qi Y, Hou S, Zhou W, Qiu C. Correlation of angiotensin-converting enzyme 2 gene polymorphisms with stage 2 hypertension in Han Chinese. Translational research. 2007;150(6):374-380.

53. Malard L, Kakinami L, O'Loughlin J, RoyGagnon M-H, Labbe A, Pilote L, et al. The association between the angiotensin-converting enzyme- 2 gene and blood pressure in a cohort study of adolescents. BMC Med Genet. 2013;14:117.

54. Chen Q, Tang X, Yu C, Chen D, Tian J, Cao Y, et al. Correlation of angiotensin-converting enzyme 2 gene polymorphism with antihypertensive effects of benazepril. Beijing da xue xue bao Yi xue ban. 2010;42(3):293-298.
55. Patnaik M, Pati P, Swain SN, Mohapatra MK, Dwibedi B, Kar SK, et al. Association of angiotensinconverting enzyme and angiotensin-converting enzyme-2 gene polymorphisms with essential hypertension in the population of Odisha, India. Ann Hum Biol. 2014;41(2):145-52.

56. Pinheiro DS, Santos RS, Jardim PCV, Silva EG, Reis AA, Pedrino GR, et al. The combination of ACE I/D and ACE2 G8790A polymorphisms revels susceptibility to hypertension: A genetic association study in Brazilian patients. PloS one. 2019;14(8): e0221248.

57. Liu C, Li Y, Guan T, Lai Y, Shen Y, Zeyaweiding A, et al. ACE2 polymorphisms associated with cardiovascular risk in Uygurs with type 2 diabetes mellitus. Cardiovascular diabetology. 2018;17:127.

58. Meng N, Zhang Y, Ma J, Li H, Zhou F, Qu Y. Association of polymorphisms of angiotensin I converting enzyme 2 with retinopathy in type 2 diabetes mellitus among Chinese individuals. Eye (Lond). 2015;29(2):266-71.

59. Fan Z, Wu G, Yue M, Ye J, Chen Y, Xu B, et al. Hypertension and hypertensive left ventricular hypertrophy are associated with ACE2 genetic polymorphism. Life sci. 2019;225:39-45.

60. Wysocki J, Ye M, Soler MJ, Gurley SB, Xiao $\mathrm{HD}$, Bernstein KE, et al. ACE and ACE2 activity in diabetic mice. Diabetes. 2006;55(7):2132-9.

61. Rabelo LA, Todiras M, Nunes-Souza V, Qadri F, Szijarto IA, Gollasch M, et al. Genetic deletion of ACE2 induces vascular dysfunction in C57BL/6 mice: role of nitric oxide imbalance and oxidative stress. PloS one. 2016;11(4):e0150255.

62. Ioana M, Ferwerda B, Farjadian S, Ioana L, Ghaderi A, Oosting M, et al. High variability of TLR4 gene in different ethnic groups in Iran. Innate immun. 2012;18(3):492-502.

63. Raj VS, Mou H, Smits SL, Dekkers DH, Müller MA, Dijkman R, et al. Dipeptidyl peptidase 4 is a functional receptor for the emerging human coronavirus-EMC. Nature. 2013;495(7440):251-4.

64. Nargis T, Kumar K, Ghosh AR, Sharma A, Rudra $\mathrm{D}$, Sen D, et al. KLK5 induces shedding of DPP4 from circulatory Th17 cells in type 2 diabetes. Molecular metabolism. 2017;6(11):1529-1539.

65. Kleine-Weber $H$, Schroeder S, Krüger N, Prokscha A, Naim HY, Müller MA, et al. Polymorphisms in dipeptidyl peptidase 4 reduce host cell entry of Middle East respiratory syndrome 
coronavirus. Emerg Microbes Infect. 2020;9(1):155-168.

66. Asselta R, Paraboschi EM, Mantovani A, Duga S. ACE2 and TMPRSS2 variants and expression as candidates to sex and country differences in COVID-19 severity in Italy. Aging (Albany NY). 2020;12(11):10087-10098.

67. Calcagnile M, Forgez P, Iannelli A, Bucci C, Alifano M, Alifano P. ACE2 polymorphisms and individual susceptibility to SARS-CoV-2 infection: insights from an in silico study. bioRxiv. 2020.

68. Yu L, Yuan K, Phuong HTA, Park BM, Kim SH. Angiotensin-(1-5), an active mediator of renin-

angiotensin system, stimulates ANP secretion via Mas receptor. Peptides. 2016;86:33-41.

69. Zhang H, Baker A. Recombinant human ACE2: acing out angiotensin II in ARDS therapy. Crit Care. 2017;21(1):305.

70. Khan A, Benthin C, Zeno B, Albertson TE, Boyd $\mathrm{J}$, Christie JD, et al. A pilot clinical trial of recombinant human angiotensin-converting enzyme 2 in acute respiratory distress syndrome. Crit Care. 2017;21(1):234.

71. Yan R, Zhang Y, Li Y, Xia L, Guo Y, Zhou Q. Structural basis for the recognition of the SARS-CoV2 by full-length human ACE2. Science. 2020;367(6485):1444-1448. 